\title{
Good reporting practices
}

\author{
by S.M. Rupprecht
}

\section{Synopsis}

The SAMREC Code sets out the minimum standard for the Public Reporting of Exploration Results, Mineral Resources, and Mineral Reserves. When making a declaration the Competent Person (CP) must disclose relevant information concerning the status and characteristics of a mineral deposit that could materially influence the economic value of the deposit and promptly report any material changes. The Johannesburg Stock Exchange (JSE) Listing enlists Panel Readers to review all CP Reports and annual reports for their compliance with the SAMREC Code and Section 12 of the JSE Listing Requirements.

The JSE Readers Panel assists in achieving reporting compliance. However there are still many Public Reports that are not formally reviewed. Thus, the SAMREC Code is largely reliant on self-regulation. Although Clause 11 of the SAMREC Code makes provision for complaints made in respect of Public Reporting, complaints are rarely made. Yet, noncompliant reporting remains an issue within the southern African mineral industry.

This paper investigates compliance of Public Reports and some of the common compliance issues currently being experienced. The paper also discusses methodologies to improve compliance and Public Reporting, such as self-regulation, coaching and training, and other means to promote good reporting compliance.

Keywords

Public Reporting, good practice, self-regulation.

\section{Introduction}

The South African Code for the Reporting of Exploration Results, Mineral Resources and Mineral Reserves (The SAMREC Code) contributes to promoting the minimum requirements of Public Reporting. A declaration in terms of The SAMREC Code requires the Competent Person $(\mathrm{CP})$ to be prepared to defend themselves to their peers. The Code relies on this peer review process and is therefore effectively self-policing. The effectiveness of this self-policing has been debated since the inception of the Code, and although it is sometimes seen as ineffective, self-regulation is the preferred method to monitor Public Reporting.

The Poseidon Nickel bubble of 1970 and the Bre-X scandal of 1997 motivated the creation of international reporting codes, which provide investors, potential investors, and other stakeholders with a sense of confidence in statements made by promoters and owners of mineral projects. Consequently, the aim of the SAMREC Code is to maintain the trust of investors and other interested parties by promoting high standards of Public Reporting. The SAMREC Code is meant as a minimum reporting standard and advises CPS to report 'too much information rather than too little' (Clause 32 of the SAMREC Code).

Opponents to the monitoring of Public Reporting practices are of the opinion that the Code is presented as a guideline and therefore regulating reporting practices is not necessary. Furthermore, opponents feel that some responsibility must be placed on the investor to be diligent when investing in an exploration or mineral company. The author does not concur with the above opinions, as the mineral industry relies on investments to support project development and, furthermore, the industry historically had a tarnished reputation. Mark Twain in the 1880s famously defined a mine as 'a hole in the ground with a liar on top'. Events such as the 1970s Poseidon Nickel boom-to-bust, Bre-X, and Enron highlight unscrupulous or fraudulent behaviour. In South Africa, recent failures such in coal, platinum, and gold projects and other commodities have eroded investor confidence, for example the delisting of Miranda Coal and closure of Burnside gold mine. In an industry that requires investor capital, often as seed money to fund early exploration or development projects, ensuring investor confidence is paramount.

Public companies listed on the Johannesburg Stock Exchange (JSE) must adhere to the ongoing reporting requirements in terms of Section 12.11 of the JSE Listing Requirements. When a company reports

* University of Johannesburg, South Africa.

(C) The Southern African Institute of Mining and Metallurgy, 2017. ISSN 2225-6253. This paper was first presented at the SAMREC/SAMVAL Companion Volume Conference 'An Industry Standard for Mining Professionals in South Africa', 17-18 May 2016, Emperors Palace, Johannesburg 


\section{Good reporting practices}

according to the SAMREC Code, the public should have a sense of confidence that the information that has been reported is relevant, factually correct, and provides full disclosure. Fortunately, most companies adhere to the principles and guidelines of the SAMREC Code. In some cases, minor oversights may occur but generally companies observe the underlying values of the Code. Regrettably, there is a minority of companies that do not understand the importance of good ongoing reporting and fail to adhere to industry best practice. In these cases, Exploration Results, Mineral Resources, and Mineral Reserves are reported in an inappropriate manner, leaving the public uninformed as reporting fails to comply with the Code fully, misinterprets data, distorts information, or fails to disclose material information fully. The mineral industry is a difficult enough investment without being encumbered by poor disclosure, non-transparency, and poor quality and/or incompetent reporting.

This paper discusses the issues around compliant Public Reporting and the SAMREC Code. The paper also discusses the governing principles of the Code, self-regulation and complaints procedures, and provides examples of noncompliant reporting. Reference is made to the revised 2016 SAMREC Code and recommendations made going forward regarding Public Reporting, self-regulation, and teaching and mentoring of industry professionals.

\section{Governing principles of the Code}

In the course of Public Reporting, CPs sometimes overlook the governing principles of the SAMREC Code, i.e. Transparency, Materiality, and Competence (Figure 1).

Materiality signifies that all relevant information should be made available and that reasoned and balanced reporting should be undertaken. One of the main purposes in developing the Codes was to ensure that various stakeholders, investors, and their professional advisors would be provided with sufficient information for the purpose of making a reasoned and balanced decision. Critical to Public Reporting is the principle that any material aspects for which the presence or absence of comment could affect the public perception or value of the mineral occurrence must be disclosed.
Transparency requires that the $\mathrm{CP}$ provide sufficient information, which is clear and unambiguous, and that the $\mathrm{CP}$ does not mislead or omit material information. As a rule, it is better for the $\mathrm{CP}$ to provide too much information rather than too little. Transparent reporting provides the public with confidence.

Competency requires that all technical work conducted is done by suitably qualified and experienced persons who are subject to an enforceable professional code of ethics and rules of conduct. It is important that the $\mathrm{CP}$ is not unduly affected by outside influences and remains able to present a fair and accurate report. Persons undertaking the role of a $\mathrm{CP}$ must be capable of defending their professional opinions and not be intimidated by interested parties.

CPs, executives, and other interested parties of publicly listed companies are reminded that the Code sets out the required minimum standards for Public Reporting. CPs, as authors, must insist that they provide written approval (JSE Listing Requirement) of specific documentation that is referred to in a Public Report or statement. The CP must be satisfied as to the form, content, and context in which that documentation is to be included in a Public Report. As a reminder to the reader, the Code (Clause 3) defines Public Reports as follows:

Public Reports are all those reports prepared for the purpose of informing investors or potential investors and their advisers and include but are not limited to companies' annual reports, quarterly reports and other reports included in JSE circulars, or as required by the Companies Act. The code also applies to the following reports if they have been prepared for the purposes described in Clause 3: environmental statements; information memoranda; expert reports; technical papers; website postings; and public presentations. And T8 (A)(ii) Announcements by companies should comply with the SAMREC Code, where applicable, and insofar as they relate or refer to a Competent Person's report they should: (a) Be approved in writing in advance of publication by the relevant Competent Person.

Unfortunately, Clause 3 is often overlooked by companies. Some Public Reports fail to comply with the above clause and a number of public statements fail to gain approval from the responsible CP prior to the announcement.

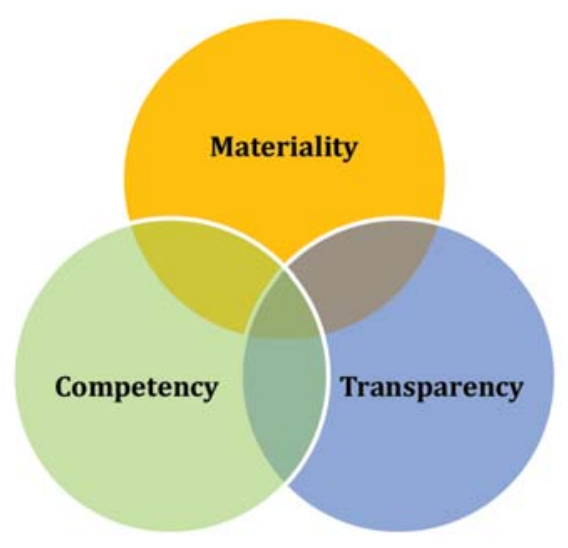

Figure 1-Underlying principles of the SAMREC Code 


\section{Good reporting practices}

In the context of complying with the principles of the Code, the CP is required to comment on the relevant sections of Table 1 of the SAMREC Code. The 2016 SAMREC Code introduces, similar to the 2012 JORC Code, an 'if not, why not' approach to the reporting as per Table 1 . This necessitates that each item listed in the table be discussed, and if not discussed then the $\mathrm{CP}$ must explain why it has been omitted from the documentation. This additional requirement to the Code improves transparency and ensures that the Public Report is clear to the reader (public) and that all items have been considered and have been addressed or resolved.

\section{Compliance}

In terms of Public Reporting, compliance requires reporting in accordance with the principles and guidelines of the SAMREC Code. The importance of compliance is the underlying requirement to provide the public with confidence. Based on discussion held within the SAMREC Committee, some mining professionals believe that the Codes are becoming overly onerous, while others believe that CP Reports (CPRs) should be made simpler and easier to complete, advocating the use of a 'short form' CPR. The author rejects the above premise and stresses the need for comprehensive and fully disclosed Public Reporting. CPRs and other Public Reports, including news releases, should not be taken lightly, noting that Public Reports must ensure that information provided is unambiguous and provide sufficient information for a reasonable person to make an informed decision on the viability of a project and whether to invest or disinvest. A short form report, basically equivalent to an executive summary, is incapable of providing sufficient detail to sufficiently inform an investor.

\section{Declaration of competency}

One cannot discuss compliance with the SAMREC Code without discussing competency of the CP. The glossary of terms as provided in the SAMREC Code has no definition provided for competency, yet competency is one of the fundamental components of the Code. Competency, as described in Clause 4 of the SAMREC Code, is as follows:

'The Public Report is based on work that is the responsibility of suitably qualified and experienced persons who are subject to an enforceable Professional code of Ethics'.

Although Clause 9 of the Code does provide clarity on the definition of a $\mathrm{CP}$ it relies on the individual to act competently.

'A Competent Person is a person who is registered with SACNASP, ECSA or SAGC, IMSSA, or is a Member or Fellow of the SAIMM, the GSSA or a RPO'. 'A Competent Person must have a minimum of five years' experience relevant to the style of mineralisation and type of deposit or class of deposit under consideration and to the activity he or she is undertaking'.

For a number of years the JSE has been requesting a registration list for CPs. The reasoning behind this drive is to improve the quality of Public Reporting, the objective being that only persons that have demonstrated their 'competency' would be able to provide CPRs to the JSE. To date this registration has not materialized, as many CPs believe that there is sufficient regulation or guidelines in place to ensure competence - the real issue is non-compliance in reporting and the lack of discipline for poor reporting practices. Selfregulation is seen as the preferred method of control, but it requires peers to monitor CPs' work and to report noncompliance.

Some professionals believe that the onus on competency should lie with statutory registration bodies such as SACNASP, SAGC, IMSSA, or ECSA. The issue of competency is sometimes confused with the fact that a CP must be a member of ECSA, SACNASP, SAGC, IMSSA, or member/fellow of the SAIMM, GSSA or a recognized professional organization (RPO), all of which have enforceable disciplinary processes including the power to suspend or expel a member/fellow. This is important in that these professional organizations provide an enforceable Professional Code of Ethics, which is a basic requirement for a CP. Although these organizations have disciplinary powers, they in themselves do not determine whether a person is competent. The responsibility of deeming oneself as competent relies on the individual as the 'Competent Person should be clearly satisfied in their own mind that they could face their peers and demonstrate competence in the commodity, type of deposit and situation under consideration' (SAMREC Code, Clause 10).

It is up to a CP's peers to ensure that indeed authors of technical (Public) reports act in a competent, responsible, and ethical manner. The CP must demonstrate their own competency applying to a Code of Ethics and if in doubt a person should either seek the opinion from appropriately experienced peers or should decline to act as a CP for that specific job.

\section{Role of the JSE Readers Panel}

The role of the JSE Reader is to ensure that a CPR or annual report is conducted in accordance with the requirements of the SAMREC and SAMVAL Codes, and the JSE Listing Requirements, indicate errors in the text, and indicate whether plans and diagrams accompanying the Public Report support the content of the report. The JSE Reader must be satisfied that the Competent Person or Competent Valuator complies with the professional registration requirements and experience as set out in Clause 7 to 10 of the SAMREC Code and/or Clause 9 and 10 of the SAMVAL Code.

The JSE Reader also must ensure that the Competent Person/Competent Valuator, in terms of a CPR, has correctly referenced the SAMREC and SAMVAL Code (Table 1) or JSE Listing Requirements in the CPR or annual report.

The Reader's job is not to provide sign-off on the technical aspects of the work nor validate the conclusions of the CPR. It must be acknowledged that there is an element of peer review in the process of ensuring that technical work makes sense and is fair and reasonable. For example, the JSE Readers guidelines state that 'the Reader should comment on issues which, based on his/her experience appear technically incorrect or inadequately covered'. However, in the end the CPR remains the responsibility of the author(s).

The JSE Readers Panel review process is viewed by other countries as a good process. However, JSE Readers Panel reviews are only activated in certain situations and not all 


\section{Good reporting practices}

published CPRs are reviewed, especially those conducted for companies not publicly listed. The reader must understand that many CPRs have not been formally reviewed.

Furthermore, the JSE Readers review process is not without its problems. One of the dilemmas with the Readers review process is that a CPR encapsulates a number of areas that may stretch the capabilities of a single Reader. For example, the Reader may be required to be knowledgeable in mineral resources, geotechnical engineering, mine engineering, ventilation, metallurgical processes, environmental, infrastructural, marketing, governmental and social aspects, as well as the valuation of mineral projects. It may be prudent for the JSE to introduce more than one reader to conduct reviews of CPRs, thereby improving the overall review process. However, it must be recognized that ultimately the CPR remains the responsibility of the $\mathrm{CP}(\mathrm{s})$.

As of 2014, the JSE Readers Panel has also begun to review annual reports of mineral and exploration companies to ensure compliance with the ongoing reporting requirements in terms of Section 12.11 of the JSE Listing Requirements. The second year of reviewing annual reports has generally seen an improvement in compliance with the JSE Listing Requirements [SAMREC Code], however, compliance still can improve.

\section{Complaints procedure}

Professionals when coming across noncompliant Public Reports need to consider if the breach warrants action. The SAMREC Code provides a means to make formal complaints, and Clause 11 states 'complaints in respect of the Public Report of a Competent Person will be subject to the complaints procedures of the [The SAMCODE Standards Committee] SSC.'

The written complaint will be referred to the Complaints Sub-committee, which will review the complaint with the complainant so as to best define the nature of the alleged breach; identify the correct professional/statutory/certifying organization where the complaint needs to be lodged; and assist the complainant to lodge their grievance in the prescribed manner of the applicable organization. The relevant body may be any of the following: SACNASP, ECSA, PLATO (now the South African Geomatics Council (SAGC), the Institute of Mine Surveyors of South Africa (IMSSA), GSSA, SAIMM, or other Recognized Professional Organization (RPO) to which the $\mathrm{CP}$ or Competent Valuator is affiliated (Learned Society or Statutory Body).

The Complaints Sub-committee will also be available to assist the ethics/disciplinary committee of the professional/statutory/certifying organization in understanding and/or investigating the nature of the alleged SAMCODES-related violation, if requested to do so by that organization.

The difficulty in managing the quality of Public Reports has been the reluctance of mining professionals to regulate their peers and to ensure that Public Reports properly adhere to the Code. The number of noncompliant Public Reports observed by the author indicates that there are members of the mineral industry that are not concerned with compliance. Perhaps this is due the fact that over the past 15 years there have only been a few complaints made to the SSC and therefore there is an attitude that little, if any action is taken for noncompliant reporting. Based on the author's experience, it appears that there are a few CPs, mining executives, and senior managers that project a laissez faire attitude toward Public Reporting and that for some there is a resistance to change reporting practices. A general review of exploration and mining company's web sites will support the above statement. Although the author could reference several indiscretions, it is not the intention of this paper to embarrass individuals or companies but rather highlight the issue.

\section{Self-regulation and complaints}

The need for self-regulation and action on noncompliant reporting has been an issue and a matter for debate since the inception of the SAMREC Code. There are many reasons for a general lack of discipline in the industry, one being that CPRs are often under confidentiality agreements. Another is the reluctance of practising CPs to make formal complaints against peers - justifying the lack of criticism under the proverb 'persons who live in glass houses shouldn't throw stones'.

Non-compliance in reporting is not limited to South Africa but is a problem for all reporting countries. A general consensus is that more focus should be on coaching and mentoring of CPs. Rather than viewing complaints as a process of taking disciplinary action or sanctions against CPs, there should be a move towards coaching and mentoring. It is proposed that the SSC, through each of the Code Committees, form a subcommittee whose primary objective is to promote short courses through the GSSA and/or SAIMM to improve knowledge of the Code and its reporting requirements.

Similarly, it may be prudent for the learned societies to publish (anonymously) corrective actions taken for noncompliant reporting. The AusIMM successfully does this and the author believes that this approach should be adopted in South Africa. It is interesting to note that if noncompliance is established, the AusIMM may impose a penalty, which may include a reprimand, mediation, and/or counselling. However, suspension of membership to the AusIMM is not imposed by the Complaints Committee, as may be the case with some of the South African professional/statutory bodies.

The Canadian Ontario Securities Commission in 2013 undertook a compliance review of 50 Technical Reports that represented approximately 10\% of the NI43-101 Technical Reports submitted over the period 30 June 2011 to 30 June 2012 (Ontario Securities Commission, 2013). The review found that $40 \%$ of the CPRs required significant changes and a further $40 \%$ were also noncompliant, requiring minor changes. Only $20 \%$ of the reports were considered compliant.

It should be noted that professional organizations do not take legal responsibility for a CP or a CPR. Professional membership does not guarantee competency for any specific technical report, nor do qualifications necessarily guarantee competency. The onus of conducting competent technical work remains with the $\mathrm{CP}$. Professional organizations are legally liable for ensuring that a person who applies for and is accepted for membership satisfies the requirements of the organization's constitution and by-laws. In doing so the 


\section{Good reporting practices}

professional organization affirms that the individual satisfies the requirements for, and has the qualifications required to be, a member and ensures that the member complies with the code of ethics of the organization. These organizations have no liability for the negligent activities of their members. This is one of the reasons for not having a register of $\mathrm{CPs}$, as the holders of the list could be held liable if a CP does not conduct compliant work.

One thing is for certain - if the mineral industry does not self-regulate its reporting then some other agency will and that could lead to non-mineral experts reviewing technical reports; an outcome that will not be good for the mining industry as a whole.

\section{Examples of noncompliance}

The following section highlights some of the more common or serious mistakes in reporting.

Figure 2 depicts a public Coal Resource and Reserve statement, which provides an example of a number of common compliance issues observed by the author. Although this statement is dated 2013, the issues highlighted remain relevant. The author has removed the project names as not to embarrass the company or the CP purposely.

\section{Reporting of Reserves}

The Coal Reserve is not subdivided in order of increasing confidence into Probable and Proved Reserves. Clauses 32, 33 , and 34 of the Code highlight the requirements when

\begin{tabular}{|c|c|c|c|c|c|c|}
\hline \multicolumn{7}{|c|}{ Summary of resources and reserves (MILLION TONS) } \\
\hline \multirow[t]{2}{*}{ SEAM } & \multicolumn{4}{|c|}{ RESOURCES } & \multicolumn{2}{|c|}{ RESERVES } \\
\hline & GTIS & Reconnaissance & Measured & TOTAL & MTIS & ROM \\
\hline 4 Seam & 0.06 & & 0.06 & 0.06 & 0.06 & 0.05 \\
\hline 2 Seam & 0.73 & & 0.69 & 0.69 & 0.69 & 0.60 \\
\hline \multirow[t]{2}{*}{4 Seam } & 0.08 & & 0.08 & 0.08 & 0.08 & 0.07 \\
\hline & 0.87 & & 0.82 & 0.82 & 0.82 & 0.72 \\
\hline 4 Seam & 0.19 & & 0.17 & 0.17 & 0.17 & 0.14 \\
\hline \multirow[t]{2}{*}{2 Seam } & 1.69 & & 1.53 & 1.53 & 1.53 & 1.27 \\
\hline & 1.88 & & 1.70 & 1.70 & 1.70 & 1.41 \\
\hline 5 Seam & 4.67 & & 4.22 & 4.22 & 4.22 & 2.24 \\
\hline 4U Seam & 2.56 & & 2.31 & 2.31 & 2.31 & 1.22 \\
\hline 4L Seam & 4.98 & & 4.50 & 4.50 & 4.50 & 2.38 \\
\hline 2 Seam & 20.36 & & 18.37 & 18.37 & 18.37 & 9.74 \\
\hline 1 Seam & 4.54 & & 4.09 & 4.09 & 4.09 & 2.17 \\
\hline \multirow[t]{2}{*}{ 1L Seam } & 1.44 & & 1.30 & 1.30 & 1.30 & 0.69 \\
\hline & 38.55 & & 34.79 & 34.79 & 34.79 & 18.44 \\
\hline 2 Seam & 40.80 & 9.79 & & & & \\
\hline 4 Seam & 61.70 & 14.81 & & & & \\
\hline
\end{tabular}

Figure 2-Example of a 2013 coal Resource and Reserve statement reporting reserves. Although not the case in this example, CPs continue to incorrectly use the term 'Proven' instead of 'Proved'. Furthermore, when reporting Coal Reserves, Mineable Tons In-situ (MTIS), ROM, and Saleable Tonnages must be reported. In the above example the Saleable Tonnage has been left out of the report, and therefore the reader is uninformed of the coal beneficiation efficiency and the planned market for the sale of the washed coal.

\section{Reporting of coal quality}

Figure 2 highlights another common occurrence in the declaration of Coal Resources and Reserves - the failure to report the quality of the coal. The above example only reports coal tonnages. According to Clause 52 of the Code, appropriate coal qualities must be reported for all Resources and Reserve categories. The selection of the quality parameters is the responsibility of the $\mathrm{CP}$ and should include parameters such as ash, volatile matter, sulphur, coking properties, calorific value, etc. The coal quality parameters also should include the basis of reporting (air-dry or dry basis, etc.), and where applicable Saleable Coal Reserves should be subdivided into the relevant coal product types.

This information is critical and without reporting coal qualities the Coal Reserve is almost useless to an investor. This reporting trend must be stopped immediately; unfortunately, many coal companies observe this trend as being sanctioned. Hopefully, through the JSE Readers Panel's review of annual reports and ongoing training this poor reporting practice will be corrected over the next couple of years.

\section{Reporting Exploration Results}

When reporting Exploration or Reconnaissance Results (Clause 20 of the SAMREC Code) the potential quantity, quality, and content should be reported as a range and should include a detailed explanation of the basis for the statement and a proximate statement that the potential quantity, quality, and content are conceptual in nature. Failure to report as a range of values and not providing a detailed explanation may be misleading to the investor, as it may appear that there is greater confidence associated with the project than actually exists. Failure to comply with Clause 20 , as seen in the provided example, remains a common oversight by some CPs and Public Reports.

\section{Inclusive and exclusive}

When both Mineral Resources and Mineral Reserves are reported the Public Report must include a statement that clearly indicates whether the Mineral Resource is inclusive of, or exclusive to those Mineral Resources that have been modified to estimate a Mineral Reserve (Clause 39). The debate on whether Mineral Resources should be reported inclusive or exclusive of the Mineral Reserve is a decade-long debate that probably will never be resolved. However, whatever the reporting position, a statement is required to avoid confusion and the possibility of the inaccurate valuation of the Mineral Resources. The above example, like many other Resource-Reserve statements, fails to disclose whether the Coal Resources are inclusive or exclusive of the Coal Reserve. 


\section{Good reporting practices}

\section{Disclosing reasonable prospects}

Although Figure 2 is only a summary of the Coal Resource and Coal Reserve, the CP's report also failed to provide commentary on the reasonableness of the projects. For example, on the only operating mine, no comment is provided whether a Life of Mine (LOM) plan has been completed or any other commentary to support the declaration of a Coal Reserve. For other projects with Coal Reserves, no mention is made if a Feasibility Study or Pre-Feasibility Study (PFS) has been conducted - a requirement in order to declare a Reserve.

The Public Reporting of a Mineral Resource estimate must provide sufficient information on how the projects have reasonable prospects for economic extraction, assumptions made to estimate economic viability, and the cut-off grade used to estimate the Mineral Resource.

\section{Declaration of Reserves based on Conceptual/Scoping Study}

In the above example more than two of the project areas declared a reserve; however the $\mathrm{CP}$ declared 'The [deleted] pillar project is still in a planning phase'. In order to declare a Reserve the company should have either conducted a PFS or a LOM Plan. This was not the case at the time of the declaration, and therefore the project should only be classified as a Coal Resource as per Clauses 33 and 34 of SAMREC Code read with Clauses 47 and 48.

A Mineral Reserve must be based on a minimum assessment of a PFS for a project or a LOM Plan for an operation, and the modifying factors applied must be realistically considered (Clause 32 ). On occasion, Mineral Reserves are declared without a PFS being completed, which can have a material effect on the project's valuation. In terms of compliance, this is one of the biggest mistakes a $\mathrm{CP}$ can make.

\section{Disclosure}

Mineral/exploration companies are required to disclose the full name, address, professional qualifications, and relevant experience of the Lead $\mathrm{CP}$ authorizing publication of the information disclosed. Informing the investor of the CP's details and experience is also important to provide the investor with confidence that the $\mathrm{CP}$ is competent. For the informed investor, knowledge of the responsible CP may influence the decision to invest or not to invest in a project.

\section{Written confirmation}

It is common for exploration/mineral companies not to include a statement that they have written confirmation from the Lead CP that the information disclosed is in accordance with the SAMREC Code and, where applicable, the JSE Listing Requirements. Again, it is hoped this poor habit will be rectified in the short to medium term.

\section{Inferred Resources}

Many Public Reports fail to comment on whether the Inferred Mineral Resource category has been included in Feasibility Studies, and if so, the impact of such inclusion. The use of large portions of Inferred Resources in a PFS is also incorrect, and can falsely elevate the value of a mineral project.

\section{Incorrect use of the term 'ore'}

The terms 'ore' or 'orebody' should be used only when a Mineral Reserve has been completed, and should be associated with Mineral Reserves and not Mineral Resources. For example, the following excerpt from a recent news release is incorrect.

The Zone 5 resource (JORC 2012 compliant) now totals an estimated 100.3 million tonnes of measured, indicated, and inferred ore grading $1.95 \%$ copper and 20 grams per tonne silver.

\section{Incorrect use of 'calculated'}

A common reporting mistake is the use of 'calculated' instead of 'estimated' when referring to Mineral Resource and Mineral Reserve statements.

\section{Comparison of previous mineral estimates}

The Code requires that a comparison of the Mineral Resource and Mineral Reserve estimates with the previous financial year/period's estimates is provided and an explanation provided of the material differences between the two declarations. This remains a common oversight by CPs.

\section{Statement by directors and future activities}

Public Reports often provide no description of future exploration activities, exploration expenditures, exploration results, and feasibility studies undertaken. Directors are required to state (or include an appropriate negative statement) on any legal proceedings or other material conditions that may impact on the company's ability to continue mining or exploration activities. Again, this statement is often overlooked in Public Reporting.

\section{Economic assumptions}

Optimistic assumptions in terms of mining rates, capital expenditure, operating costs, and revenue factors are required. Problems encountered in technical reports include the inadequate disclose of the main components of the capital cost estimate. Also, economic analysis information such as cash flows and or sensitivity analysis is sometimes omitted or lacks detail. Many of the reports do not clearly disclose the assumed metal price or factors related to the mining scenario or mineral processing recovery. Failure to provide this type of information prevents the public from conducting their own techno-economic analysis of the project.

\section{Ongoing reporting requirements}

When reading an annual report, often one will come across the following or a similar statement - 'A resources and reserves summary, which is SAMREC compliant and JSE approved, is carried in full on the [deleted] website.' The annual report must contain the full information, as required by Section 12.11, within the annual report itself. Reference to other documentation providing further detailed information for the public is fine, but should not be used to provide primary information to the public.

\section{General}

The identification of risk is mentioned in several areas of the 


\section{Good reporting practices}

Code, with a dedicated section (T6) in Table 1. Although CPs may comment on risk, seldom is the analysis conducted with the intent of truly identifying risk in the Mineral Resource and Mineral Reserve estimation. A risk assessment should incorporate all technical specialists involved in the Mineral Resource and Mineral Reserve estimation process. For example, Public Reports fail to disclose project-specific risks and uncertainties, such as the availability of infrastructure, government approvals, use of novel mining/mineral processing technology, or the potential impact of regional unrest or civil war, e.g. Central Africa. Environmental and social issues have become increasingly important in recent years and remain an area of poor commentary. Based on the guiding principles of the Code, environmental and social issues require appropriate commentary in Public Reports.

\section{Training and mentoring}

A general consensus is that more focus should be on coaching and mentoring of $\mathrm{CPs}$ in order to improve reporting compliance. Coaching and mentoring should be seen as the preferred method, rather than using disciplinary action or sanctions against CPs. Ongoing training for CPs and CVs needs to be actively pursued by professional organizations, with the price of such training kept to a minimum so that costs do not become prohibitive.

Some universities, such as the University of Johannesburg, include tuition in the area of the SAMREC and SAMVAL Codes. The Geological Society of South Africa (GSSA) conducts CPs courses once or twice a year. The JSE also has in the past provided reporting compliance courses and the SAIMM provides ad hoc presentations on the varied topics on the codes: recent examples include un update of the 2016 SAMREC and SAMVAL Codes, the application of Modifying Factors, and the Companion Volume published to coincide with the launch of the 2016 SAMREC and SAMVAL Codes.

As peers we must play a more active role in regulating our own industry. As a general observation, the mining industry needs to implement a coaching and mentoring approach, thereby uplifting reporting standards. Coaching and mentoring must not be limited to only CPs, but must also extended to exploration and mineral companies who must also abide by the SAMREC Code as well as the JSE Listing Requirements

\section{Conclusions and recommendations}

The SAMREC Code already provides guidelines to reporting, as presented in Table 1. The difficulty is that Table 1 is not properly used, as authors of CPRs fail to comply fully with the provided checklist, choosing rather to omit certain clauses of the Code. The updating of the Code should improve compliance with the introduction of the 'if not, why not' approach to reporting.

However, updating of the Code addresses only one aspect of Public Reporting compliance. The implementation of selfregulation and peer review will go a long way towards improving reporting compliance. CPs, as well as the mining industry, must realize that failure to comply with the guiding principles of the SAMREC Code not only damages the reputation of the $\mathrm{CP}$ but also the reputation of the mining profession. The mineral industry must self-regulate, otherwise others will conduct this regulatory process and almost certainly this will not be to the industry's liking or satisfaction.

Along with self-regulation, more teaching and mentoring is required to improve the overall quality of Public Reporting. A number of companies and organizations conduct training courses on a regular basis; some for commercial purposes while other learned societies such the GSSA and SAIMM present courses on a non-profit basis. In the future, courses need to focus on compliance issues, the underlying meaning and intent of the Code, and examples of good and poor reporting practices.

When CPs fail to comply with the Code and a complaint is raised, corrective action must be taken. The process should focus on corrective action rather than punishment. The process should be geared to improve reporting standards, with severe retribution served only to those individuals acting in a fraudulent or incompetent manner. Part of the process must involve educating the mining fraternity on the shortcomings in Public Reporting practices so that deficiencies can be shared and the lessons learned made public.

Any learning outcome must provide a foundation to the intent of the Code. Currently, CPs see the Code as a hurdle to be met in order to complete an assignment. All too often there appears to be a disjoint between creating a report and protecting the interests of investors. Furthermore, CPs must be capable of preserving their professional opinions and not be intimidated by interested parties.

\section{Acknowledgement}

The author would like to acknowledge the assistance and guidance provided by Mr Ken Lomberg of Pivot Mining Consultants (Pty) Ltd.

\section{References}

Ontario Securities Commission. 2013. OSC Staff Notice 43-705 - Report on Staff's Review of Technical Reports by Ontario Mining Issuers. June 2013.

RUPPRECHT, S.M. 2014. The SAMREC Code 2015 - Some thoughts and concerns. Proceedings of Surface Mining 2014 . Southern African Institute of Mining and Metallurgy, Johannesburg.

SAMREC. 2009. South African Mineral Resource Committee. The South African Code for the Reporting of Exploration Results, Minerals Resources and Mineral Reserves (the SAMREC Code). 2007 Edition as amended July 2009. Prepared by the South African Mineral Resource Committee (SAMREC) Working Group.

http://www.samcode.co.za/downloads/SAMREC2009.pdf

SAMCODE. 2009. The South African Mineral Codes. http://www.samcode.co.za/SAMCODE/SSC/Disciplinaryprocedures [Accessed: 15 April 2015].

WIKIPEDIA. 2014. Regulatory compliance.

http//www.en.wikipedia/regulatory compliance.

[Accessed 16 April 2015]. 
